\title{
Determinants of timely pregnancy dating scan in a Sri Lankan antenatal clinic setup
}

\author{
Dias $\mathbf{T}^{1,2}$, Fernando $\mathbf{A}^{1}$, Kumarasiri $\mathbf{S}^{1}$, Padeniya $\mathrm{T}^{1}$
}

\begin{abstract}
Background: Early accurate estimation of gestational age is the most important intervention in pregnancy. Ultrasound between 11 and 13 weeks is most reliable in dating. There is no uniform policy in timing of dating scan in Sri Lanka.
\end{abstract}

Objective: Aim of this study was to find out factors that determine the timely dating scan before 14 weeks in a district general hospital in Sri Lanka.

Methods: This was a prospective observational study carried out at District General Hospital in Sri Lanka. A detail history was taken in order to ascertain age, parity, menstrual history, time taken to reach the hospital, distance to the hospital, level of education and gestation at the first booking visit with public health midwife $(\mathrm{PMH})$. We offered dating scans for every pregnant mother before 14 weeks. Logistic regression analyses were performed to evaluate the association of socio-demographic factors and receiving timely dating scan before 14 weeks.

Results: A total 199 women were included for the analysis with a mean age of 26.98 years (SD 5.58). A 190 out of total recruitments (95.5\%) were booked with PHM before 14 weeks. A total of 171 (86\%) pregnant women received their first scan before 14 weeks. Logistic regression analysis demonstrated that only booking before 14 weeks with $\mathrm{PMH}$ (Odds ratio $12.272(95 \% \mathrm{Cl}, 4.563-33.000) \mathrm{p}<0.000)$ contributed significantly to receive dating scan before 14 weeks, while maternal age, parity, time taken to reach the hospital, distance to the hospital and mother's level of education did not.

Conclusion: Our study showed it is entirely possible to offer dating scan before 14 weeks even in a peripheral District General Hospital. Moreover, we demonstrated that none other than booking before 14 weeks was determined the dating scan prior to 14 weeks.

Indexed words: timing of dating scan, gestation at booking

\section{INTRODUCTION}

The accurate gestational age assessment during early pregnancy is crucial in order to time all prenatal investigations and to determine the estimated date of delivery [1]. It also gives a reference point to interpret fetal growth in later pregnancy. Any deviation of fetal growth can be interpreted in view of intrauterine

1. District General Hospital Ampara, Sri Lanka

2. Faculty of Medicine, University of Kelaniya, Sri Lanka

Correspondence: Dr Tiran Dias

MBBS MD MRCOG MD-research (London) Dip (Fetal Med) UK

Senior Lecturer in Obstetrics \& Gynaecology

Faculty of Medicine

University of Kelaniya Sri Lanka

thiran_dias@yahoo.com growth restriction or fetal macrosomia [2]. Inaccuracy in dating could have implications for management and outcomes of the pregnancy in such significant over estimation of gestational age can lead to iatrogenic prematurity whereas a significant underestimation may lead to a delay in intervention and post maturity. Traditionally, estimated date of delivery is calculated by the woman's last recorded menstrual period (LRMP) [3]. However, pregnancy dating by menstrual history cannot be used uniformly as up to $40 \%$ of women are uncertain of their menstrual dates and ovulation may not exactly correspond with the mid menstrual cycle [4]. Furthermore, last menstrual period estimates of the duration of gestation are subject to both random error and a systematic tendency to overstate the duration of gestation [5]. It has been demonstrated that the gestational age determined by ultrasound fetal crown-rump (CRL) length between 11 and 14 weeks in singleton pregnancies is similar to true gestation [6]. Second trimester dating is not accurate as first trimester dating with higher number of postdate pregnancies with later policy [7]. The International Society of Ultrasound in Obstetrics (ISUOG) has recently recommended that all pregnancies should be dated by CRL between 11 and 14 weeks [1].

Sri Lanka has been highly regarded as having well organized antenatal care with lowest maternal mortality ratio in South Asian region [8]. However, there is no national policy in timing of dating scan in Sri Lanka [8]. Two important prerequisites need to be fulfilled in achieving uniform policy of dating in any country. Firstly, expectant mothers should be referred for the dating scan before 14 weeks and secondly, scans should be offered unrestrictedly to all mothers once they come before 14 weeks. Other socio-demographic factors can also contribute for timely dating scan. The Aim of this study was to determine the association of socio-demographic factors and receiving dating scan before 14 weeks.

\section{METHODOLOGY}

This was a prospective observational study, carried out from April 2013 to May 2013 at District General Hospital Ampara. Since 2011 all Medical offices of health $(\mathrm{MOH})$ in the district have been instructed to refer all the patients before 14 weeks gestation for the dating scan. As a routine practice, we offer dating scans for every pregnant mother before 14 weeks without restricting numbers. All women who had their first antenatal scan appointment in Ampara, Padiyathalawa and Mahaoya hospitals within this time period were recruited. 
A detail history was taken in order to ascertain age, parity, menstrual history, time taken to reach the hospital, distance to the hospital, level of education and gestation at the first booking visit with public health midwife (PMH). Ultrasound examinations were carried out only by trained doctors. Fetal CRL or HC were obtained as previously described [9]. All pregnancies were dated either by fetal CRL before 14 weeks or by HC thereafter. Reasons for not attending for the dating scan were documented from women who were booked before 14 weeks and not attended for the scan before 14 weeks.

Logistic regression analyses were performed to evaluate the association between receiving dating scan before 14 weeks and age, parity, time taken to reach the hospital, distance to the hospital, level of education and gestation at the first booking visit with public health midwife. Ethical approval has been obtained from the ethics review committee of District General Hospital Ampara.

\section{RESULTS}

A total of 211 women were recruited. Of these, $12(5.7 \%)$ cases with uncertain LRMP were excluded and 199 women were included for the analysis. A mean age was 26.98 years (SD 5.58) and majority of them were primiparous $(65 \%)$. One hundred and ninety out of total recruitment $(95.5 \%)$ were booked with PHM before 14 weeks. A total of $171(86 \%)$ pregnant women received their first scan before 14 weeks. Personal issues and ignorance (15/19) were the main excuses given for not attending before 14 weeks while lack of communication was noted in 4 cases. Basic characteristics of the study group are given in table 1.

Logistic regression analysis demonstrated that only booking before 14 weeks with PMH (Odds ratio $12.272(95 \% \mathrm{CI}, 4.563-33.000)$ $\mathrm{p}<0.000)$ contributed significantly to receive dating scan before 14 weeks, while maternal age, parity, time taken to reach the hospital, distance to the hospital and mother's level of education did not (Table 2).

Table 1: Patients characteristics of the study population

\begin{tabular}{|l|c|}
\hline Mean maternal age (years, range) & $26.9(18-42)$ \\
\hline $\begin{array}{l}\text { Parity } \\
\text { - Nulliparous }\end{array}$ Multiparous & 73 \\
\hline $\begin{array}{l}\text { Level of education } \\
\text { No education }\end{array}$ & 126 \\
\hline$\quad$ Primary & 6 \\
\hline$\quad$ Tecondiary & 11 \\
\hline Timing of first ultrasound scan (weeks) & 180 \\
\hline$\quad<11$ & 2 \\
\hline$\quad$ 11-14 & 47 \\
\hline Mean time taken to reach the hospital in minutes (SD) & 124 \\
\hline Mean distance to the hospital in kilometres (SD) & 28 \\
\hline $\begin{array}{l}\text { Mean gestation at the first booking visit with public health midwife in } \\
\text { weeks (SD) }\end{array}$ & $8.5(3.3)$ \\
\hline
\end{tabular}

Table 2: Logistic regression analyses for different variables of determinants of the dating scan

\begin{tabular}{|l|l|}
\hline Determinant factors of dating scan & Odds ratio $(95 \% \mathrm{Cl})$ \\
\hline Mean maternal age & $1.051(0.962-1.148) \mathrm{p}=0.272$ \\
\hline Parity & $0.518(0.172-1.561) \mathrm{p}=0.242$ \\
\hline Level of education & $1.00(0.254-3.929) \mathrm{p}=1.00$ \\
\hline $\begin{array}{l}\text { Mean time taken to reach the hospital in minutes } \\
\text { (SD) }\end{array}$ & $0.717(0.205-2.509) \mathrm{p}=0.602$ \\
\hline $\begin{array}{l}\text { Mean distance to the hospital in kilometres (SD) } \\
\text { Mean gestation at the first booking visit with public }\end{array}$ & $1.597(0.404-6.322) \mathrm{p}=0.505$ \\
\hline health midwife in weeks (SD) & $(4.563-33.000) p<0.000$ \\
\hline
\end{tabular}

\section{DISCUSSION}

The importance of accurate dating of a pregnancy in order to optimise management cannot be overstated. A significant dating error could have potentially serious effects on management decisions and outcomes. Present antenatal care model is characterised by highly concentrated clinic visits during third trimester. This model is rapidly changing in other counties to perform a routine ultrasonography between 11 and 
13 weeks gestation for accurately determine gestational age and to determine chorionicity of multiple pregnancies and comprehensive pregnancy risk assessment at the same time [10]. This model can stratify pregnant women in to high and low risk groups. Shared care can be offered to low risk women till term while high risk women could be followed up appropriately in the specialist clinics.

Dating scan is a basic right of all pregnant women [10]. Our study demonstrated that majority of women booked early in pregnancy and they have received dating scan before 14 weeks. Very little number of women was ignorant about dating scan and this is likely due to lack of awareness of the importance of early dating scan. Moreover, our study showed that booking before 14 weeks is the only factor that contributed significantly to determine timely scan. None of other factors including distance to the hospital, time taken to reach the hospital and level of education did contribute significantly to receive timely scan before 14 weeks. The main strength of this study is that we were able to conduct this study prospectively and dedicated doctors (AF/SG) interviewed all recruited women for necessary information. Most of the scans were performed by fetal medicine foundation, United Kingdom accredited operator for first and second trimester scan (TD).

Sri Lanka is having organised antenatal care (ANC) setting with the coverage of $99 \%$ and ANC is delivered by combination of consultant obstetricians and gynaecologists in tertiary care centers and by public health midwives and medical officers of health in the primary health care setup [10]. Despite of having organised care pathway for expectant mothers mandatory routine early dating scan has not been incorporated in to our antenatal care practice. This has resulted in lack of uniformity across the country of timing of dating scan. Current practice is such that timing of dating scan is decided by the respective consultant obstetrician of the tertiary care centre and there is wide variation in practice especially in timing of the first scan [8]. Ministry of Health has recently revised the pregnancy record (H5512A) in order to optimise maternity care in Sri Lanka. Commendably, they have included a space for ultrasound dating (optional) to be filled by Consultant Obstetricians. Understandably, this step is futile without having a national policy of mandatory early dating scan. Moreover, all consultant Obstetricians led units need to arrange logistics to scan pregnant women before 14 weeks without restricting numbers. Some units may need to be equipped with adequate staff and technology.

\section{CONCLUSION}

Our study showed it is entirely possible to offer dating scan before 14 weeks even in a peripheral District General Hospital. Moreover, we demonstrated that none other than booking before 14 weeks was determined the dating scan prior to 14 weeks. A systematic approach is needed to introduce dating scan and this should be complemented with dissemination of knowledge among patients and health staff regarding the importance of first trimester scan. This will require coordinated efforts of health authorities and professional organizations.

\section{REFRENCES}

1. Salomon LJ, Alfirevic Z, Bilardo CM, Chalouhi GE, Ghi T, Kagan KO, Lau TK, Papageorghiou AT, Raine-Fenning NJ, Stirnemann J, Suresh S, Tabor A, TimorTritsch IE, Toi A, Yeo G; International Society of Ultrasound in Obstetrics. ISUOG practice guidelines: performance of first-trimester fetal ultrasound scan. Ultrasound Obstetrics and Gynaecology. 2013;41(1):102-13. doi: 10.1002/ uog. 12342
2. Gardosi JFetal growth: towards an international standard. Ultrasound Obstetrics and Gynaecology. 2005. 26(2):112-4.

3. Naegele FC. 1812. Erfahrungen und abhandlungen aus dem gebiethe der krankheiten des weiblichen geschlechtes. nebst grundziigen einer methodenlehre der geburt shillfe. Mannheim: Loeffler,280-1.

4. Hunter A L. Issues in Pregnancy Dating: Revisiting the Evidence. Journal of Midwifery \& Women's Health. 2009;54(3):184-190.

5. Savitz DA, Terry JW Jr, Dole N, Thorp JM Jr, Siega-Riz AM, Herring $A H$. Comparison of pregnancy dating by last menstrual period, ultrasound scanning, and their combination. American Journal of Obstetrics and Gynecology. 2002;187(6):1660-6.

6. Dias T, Mahsud-Dornan S, Thilaganathan B, Papageorghiou A, Bhide A Firsttrimester ultrasound dating of twin pregnancy: are singleton charts reliable? British Journal of Obstetrics and Gynaecology 2010; 117(8):979-84.

7. Neilson JP. Ultrasound for fetal assessment in early pregnancy. Cochrane Database Syst Rev 2001, Art. No:CD000182.DOI:10.1002/14651858. CD000182.

8. Dias $T$, Weerasinghe $A$, Amarathunga $P$, De Silva C Thilaganathan B. Twin pregnancy chorionicity determination in a tertiary care setting. Ceylon medical journal in press.

9. Loughna P, Chitty L, Evans T, Chudleigh T. Fetal size and dating: charts recommended for clinical obstetric practice. Ultrasound 2009;17(3)161-7.

10. Goonewardene M, Dias T. Antenatal care: paradigm changes over the years. Ceylon Medical Journal 2013;58(2):47-50 